\title{
Chronic subdural haematoma, an unusual injury from playing basketball
}

\author{
Thomas M Keller, Martin C Holland
}

\begin{abstract}
Although the literature records instances of acute epidural haematoma and acute subdural haematoma related to playing basketball, there has not been a report of chronic subdural haematoma as a basketball injury. With the burgeoning interest in this sport in the United Kingdom and Europe, the possibility of this particular neurotrauma increases. Such an injury, along with the diagnosis and management of this often insidious lesion, is documented in this case report. (Br F Sports Med 1998;32:338-339)
\end{abstract}

Keywords: subdural haematoma; basketball injury; computed tomography

Sports related nervous system injuries are decidedly uncommon in basketball players. ${ }^{1}$ Nevertheless, the literature does report cases of acute epidural haematoma and acute subdural haematoma that required urgent neurosurgical intervention in patients injured during basketball contests. $^{23}$ To date, the development of a chronic subdural haematoma complicating a blow to the head by a basketball during a game has not been described. This report documents such a case and outlines diagnosis and treatment of this insidious injury, the identification of which may tax the diagnostic acumen of the treating physician.

\section{Case report}

The patient, a 43 year old man, was playing basketball on December 22 1996. After missing a pass with his hands, he was struck hard on the right side of the face with the ball. He was stunned, fell to the ground for two minutes, had an emesis, but did not lose consciousness. Previously, he had been in excellent health. He denied using alcohol or drugs before or during the game.

Over the next week, bifrontal throbbing headaches gradually developed. They were worse in the morning. Two weeks after injury, the headaches became so severe that they precluded the patient from his normal employment as a carpet layer. Very severe headaches would trigger emesis.

On January 22 1997, the patient presented to the hospital emergency department for evaluation. In spite of his headaches, he was noted to be alert and oriented. Except for slight upper extremity dysmetria, the neurological examination was normal. A diagnosis of migraine headache was made. He was given Tylenol with codeine and Compazine and referred to the neurology clinic.

In spite of the medications and bed rest, the headaches continued. On February 1, a

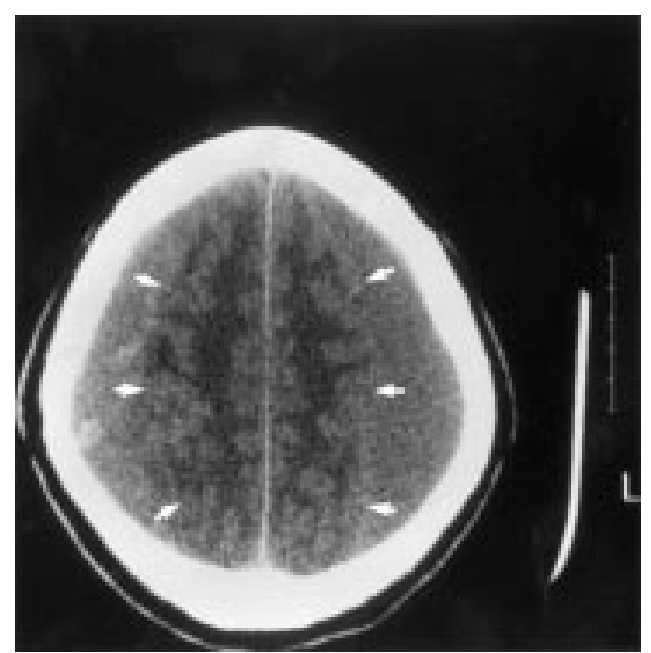

Figure 1 Non-contrast cerebral computed tomography scan showing bilateral frontoparietal subdural haematomas (arrows outline cerebral surface).

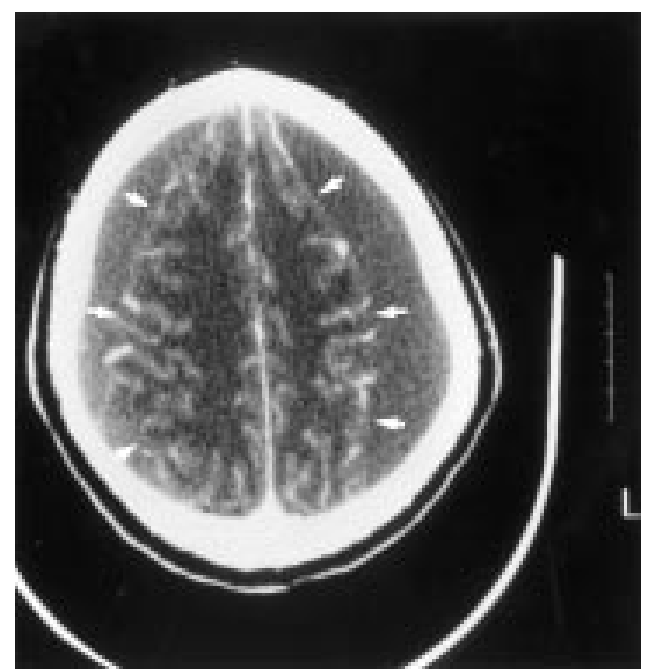

Figure 2 Contrast enhanced cerebral computed tomography scan showing demarcation of brain from extra-axial fluid collections (arrows show brain interface with subudral fluid). 
cerebral computed tomography (CT) scan disclosed the presence of bilateral frontoparietal subdural haematomas (fig 1). A contrast enhanced CT scan further delineated the extra-axial cerebral fluid collections (fig 2).

The patient, initially hesitant to pursue surgical treatment, returned home. Persistent severe headaches finally prompted him to consent to surgery. On February 11, the subdural collections were drained via bilateral parietal trephinations. The fluid had the typical appearance of "crank case oil." Jackson-Pratt drains were inserted to facilitate evacuation of the remaining haematoma. For two days after the operation, the patient was kept in bed with his head flat to promote optimal drainage of the fluid and brain re-expansion.

A postoperative CT scan on February 12 showed that the haematomas were fully evacuated. The subdural drains were removed on the third postoperative day. He was referred to rehabilitation for a short course of gait retraining.

Six weeks after his operation for chronic subdural haematoma, the patient was seen in the neurosurgery clinic. $\mathrm{He}$ was free of headaches and displayed a completely normal neurological examination. He plans to return to his trade as a carpet layer, but decided to retire from basketball.

\section{Discussion}

Intracranial haematomas in the subdural space of the brain, subdural haematomas, are classified as chronic when the initial haemorrhage produces no clinical signs or symptoms for several weeks or longer. Although subdural haematomas were first recognised as a pathological entity in the seventeenth century, the classic paradigm of the pathophysiology of these lesions as a haemorrhagic and inflammatory process ("pachymeningitis haemorrhagica," "pachymeningitis interna chronica") was described by Virchow in $1863 .{ }^{45}$

Unlike acute or subacute subdural haematomas, which generally produce prominent neurological signs and symptoms soon after a brain injury, chronic subdural haematomas produce clinical manifestations of extreme variability with no characteristic syndrome or even antecedent history of head trauma. Indeed, the term coined by William Osler for the myriad clinical findings produced by advanced untreated syphilis, the "great masquerader," is equally applicable to the protean nature of the symptomatology of chronic subdural haematomas. ${ }^{6}$ This premise is corroborated by the analysis in 1940 of autopsy protocols from Massachusetts mental hospitals, where 245 out of 3100 insane patients $(7.9 \%)$ were found to have subdural haematomas. ${ }^{7}$ In addition, cited in the literature are cases of transient ischaemic attacks and a case report of severe depression caused by the unsuspected presence of these insidious lesions. $^{89}$

Until recent times, in many instances the operative therapy of these lesions offered daunting challenges. Even as recently as 1973, bilateral exploratory trephinations were recom- mended to make a diagnosis if cerebral angiography was inconclusive or unavailable. ${ }^{10}$ The advent of cerebral CT has revolutionised neurological diagnosis and tremendously facilitated the detection of intracranial haematomas. ${ }^{11}$

The necessity to administer intravenous contrast enhancing agents for the CT diagnosis of subacute or chronic subdural haematomas is illustrated in this case report, as the extra-axial blood density attenuates with time and the haematoma gradually appears isodense with the adjacent cerebral tissue. ${ }^{12}$ After the establishment of the correct diagnosis, the mainstay of therapy is operative via trephination and subdural drain insertion, or craniotomy if the haematoma is too organised to allow evacuation by simple drainage. ${ }^{13}$ Non-operative management is possible in very select cases, but the patients must be followed very closely for any evidence of neurological deterioration and in conjunction with a neurosurgical consultant. ${ }^{14}$

Thus it would appear that even apparently trivial injuries to the head produced by a blow with a basketball can produce potentially devastating intracranial pathology. It is reassuring that in a study of a professional basketball team carried out from 1973 to 1980, injuries to the head and face comprised only $12 \%$ of the total, and only one player in the entire time period suffered a cerebral concussion. ${ }^{15}$ Nevertheless, the physician evaluating an athlete with a history of head trauma, albeit mild, who complains of headache and exhibits a paucity of neurological findings, should not hesitate to utilise the convenience and accuracy of cerebral CT to quickly identify acute or delayed intracerebral pathology. This recommendation carries greater emphasis for sports involving greater risk of neurological injury such as boxing, football, and sky diving.

1 Lehman LB. Nervous system sports-related injuries. Am $\mathcal{F}$ Sports Med 1987;15:494-9.

2 Datti R, Gentile SL, Pisani R. Acute intracranial epidural haematoma in a basketball player: a case report. Br $\mathcal{F}$ Sports Med 1995;29:95-6.

3 Tudor RB. Acute subdural hematoma following a blow from a basketball. Am f Sports Med 1979;7:136.

4 Wepfer JJ. Observationes anatomicae, ex cadaveribus eorum, quos sustulit apoplexia. Schaffhausen, Switzerland: JC Scuteri, 1658:1-20.

5 Virchow R. Die Blutgeschwülste (Hämatome). In: Die Krankhaften Geschwülste. Berlin: August Hirschwald, 1863:

6 Osler, W, Churchman JW. Syphilis. In: Osler W, ed. Modern medicine, vol 3. Philadelphia: Lea Brothers \& Co., 1907:436-521.

7 Allen AM, Moore M, Daly BB. Subdural hemorrhage in patients with mental disease. N Engl f Med 1940;223:324-

8 Welsh JE, Tyson GW, Winn HR, et al. Chronic subdural hematoma presenting as transient neurologic deficits. Stroke 1979;10:564-7.

9 Alarcon RD, Thweatt RW. A case of subdural hematoma mimicking severe depression with conversion-like symptoms. Am F Psychiatry 1983;140:1360-1

10 Thomas LM, Gurdjian ES. Intercranial hematomas of traumatic origin. In: Youmans JR, ed. Neurological surgery. Philadelphia: WB Saunders Co., 1973: 960-8.

11 Ambrose J. Computerized x-ray scanning of the brain. $f$ Neurosurg 1974;40:679-95.

12 Tsai FY, Huprich JE, Segall HD, et al. The contrastTsai FY, Huprich JE, Segall HD, et al. The contrasthematoma. F Neurosurg 1979;50: 64-9.

13 Becker DP, Gade GP, Young HP, et al. Diagnosis and treatment of head injury in adults. In: Youmans JR, ed. Neurological surgery. Philadelphia: WB Saunders Co., 1990: 2017-148.

14 Bender MB, Christoff N. Nonsurgical treatment of subdural hematomas. Arch Neurol 1974;31:73-9.

15 Henry JH, Lareau B, Neigut D. The injury rate in professional basketball. Am f Sports Med 1982;10:16-18. 


\section{Bilateral stress fractures of the ulnae in a Kendo (Japanese fencing) player}

Takashi Sujino, Takashi Ohe, Masanobu Shinozuka

Abstract

A case of bilateral stress fractures of the ulnae in a Kendo (Japanese fencing) player is reported; the mechanism of the fractures, particularly the difference in the site of fracture between the right and left ulna, is discussed.

(Br F Sports Med 1998;32:340-342)

Keywords: stress fracture; ulna; bilateral; Kendo (Japanese fencing)

Stress fractures of the ulna are uncommon, but unilateral fractures of the diaphysis of the ulna in athletes from various sports have previously been reported. ${ }^{1-8}$ There have been no reports of bilateral stress fractures of the diaphysis of the ulnae caused by sports activities in the English literature. The following is a case report of bilateral stress fractures of the diaphysis of the ulnae in a Kendo (Japanese fencing) player.

\section{Case report}

A 15 year old right handed male Kendo player had a three week history of right mid forearm pain which developed after a week of hard training at a special camp. He was a beginner at the sport and the training camp was his first

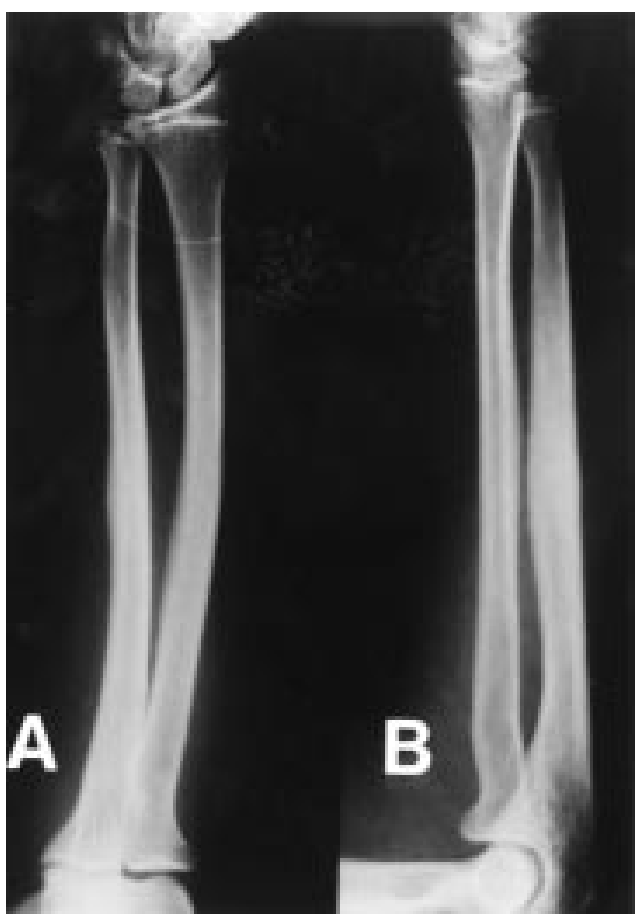
3 June 1998
Dr T Ohe, 687-4, Natogaya, Kashiwa-shi, Chiba-ken 277, Japan.

Accepted for publication

Department of

Orthopaedic Surgery,

Japan

T Sujino

T Ohe

M Shinozuka

Correspondence to: Natogaya Hospital,
Figure 1 Initial anteroposterior (A) and lateral (B) radiographs of the right forearm showing a mildly sclerotic lesion accompanied by periosteal new bone formation at the middle third of the right ulna.

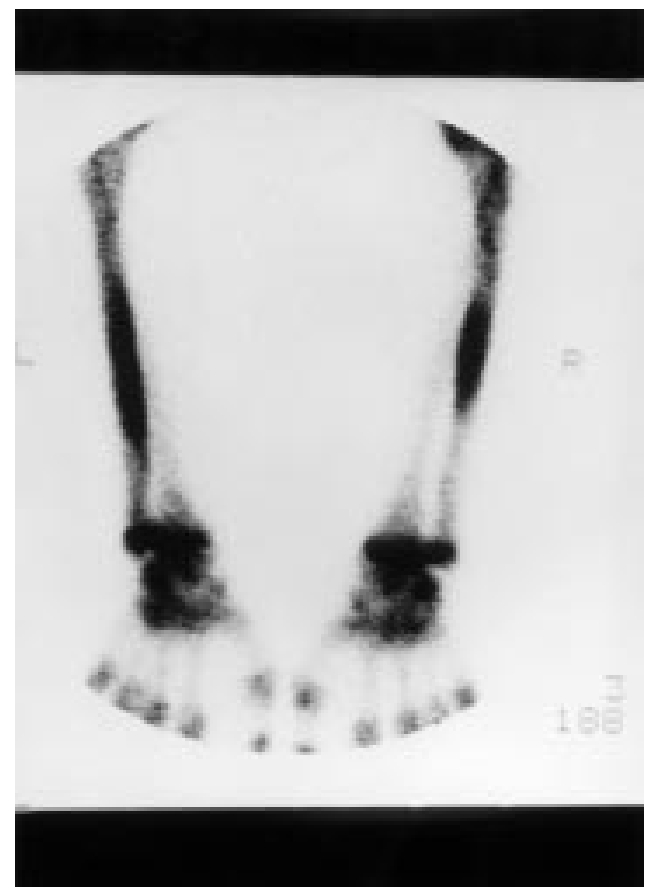

Figure $2{ }^{99_{m}}$ Tc bone scan showing a very intense increase in tracer concentration localised at the middle third of the right ulna and spread out at the junction of the middle and distal thirds of the left ulna.

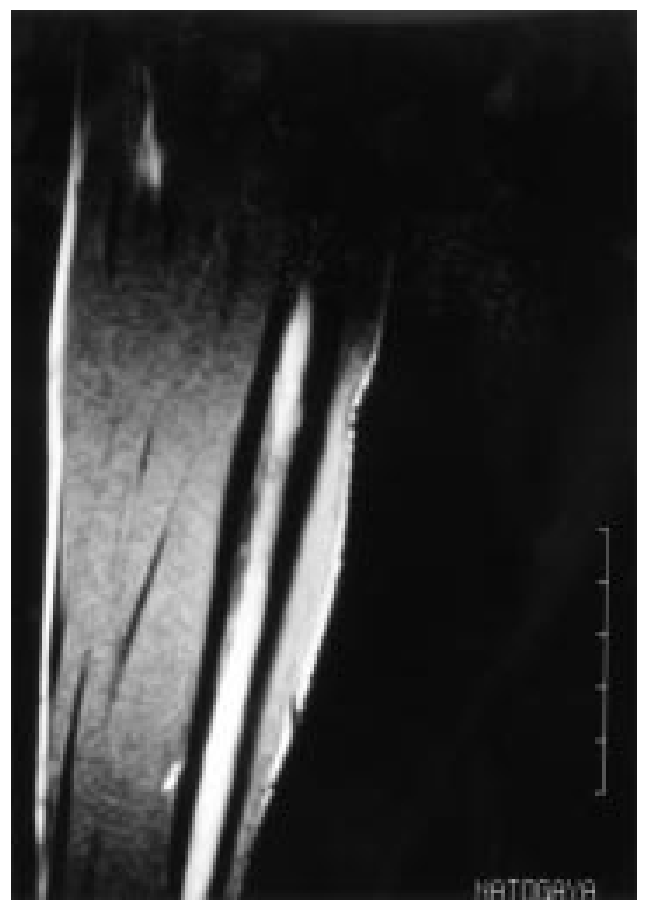

Figure 3 T1-weighted magnetic resonance image showing cortical thickening and an area of low signal intensity in the intramedullary space. 


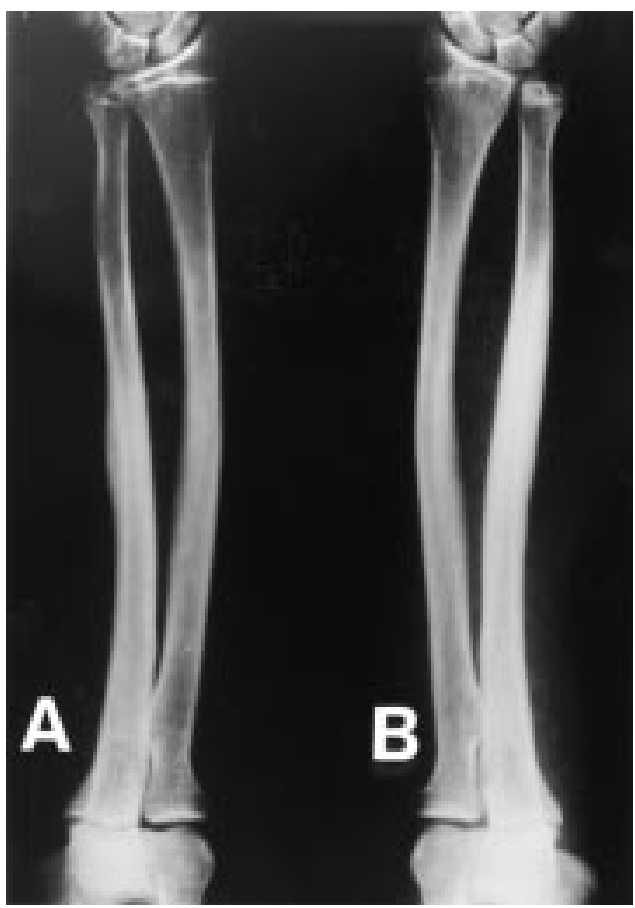

Figure 4 Anteroposterior radiographs of the right $(A)$ and left $(B)$ forearm four weeks after the onset of symptoms showing further periosteal new bone formation in the right ulna and a broad sclerotic lesion at the junction of the middle and distal thirds of the left ulna.

experience. He denied the occurrence of any specific incident of trauma, such as repeated contact or blows to the forearm from an opponent. The training mainly consisted of repeated swinging of the sword. He had tenderness and a swelling on the middle third of the right ulna.

Radiographs showed a mildly sclerotic lesion accompanied by periosteal new bone formation at the middle third of the right ulna (fig 1). Because a stress fracture of the ulna was strongly suspected, we advised him to stop training. He decreased his training, but did not stop, and after three weeks re-presented complaining of continuous pain.

A technetium-99m $\left({ }^{99 m} \mathrm{Tc}\right)$ scan and magnetic resonance imaging were performed. The ${ }^{99 \mathrm{~m}} \mathrm{Tc}$ scan showed a very intense increase in tracer concentration localised at the middle third of the right ulna and it had spread at the junction of the middle and distal thirds of the left ulna (fig 2). Magnetic resonance imaging showed cortical thickening and an area of low signal intensity in the intramedullary space on T1-weighted images (fig 3). In blood tests, alkaline phosphatase activity was slightly increased. Radiographs showed further periosteal new bone formation at the middle third of the right ulna and a broad sclerotic lesion at the junction of the middle and distal thirds of the left ulna. No fracture line was identified in either ulna (fig 4).

A diagnosis of bilateral stress fractures of the ulnae was made. The patient was immediately prohibited from exercising and instructed to rest. Eight weeks later, the pain had subsided and the tenderness had disappeared. $\mathrm{He}$ was allowed to return to Kendo training. Twelve months later, the fracture was completely

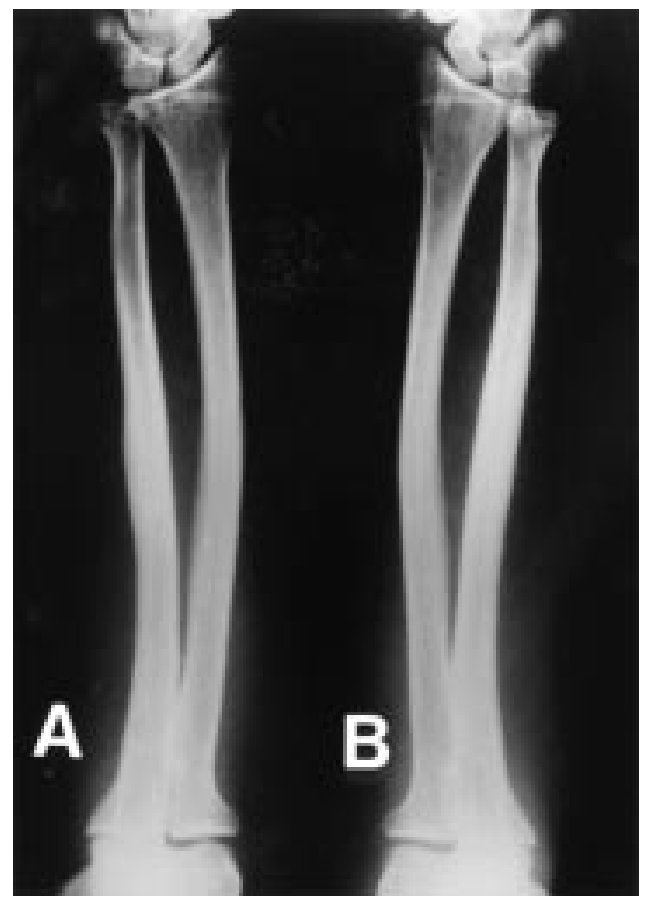

Figure 5 Anteroposterior radiographs of the right $(A)$ and left (B) forearm after 12 months showing only a slight cortical thickening.

healed. Radiographs showed only a slight cortical thickening (fig 5). There was complete absence of pain.

\section{Discussion}

Bilateral stress fractures of the ulnae are extremely rare. There is no previous report in the English literature, and only two cases have
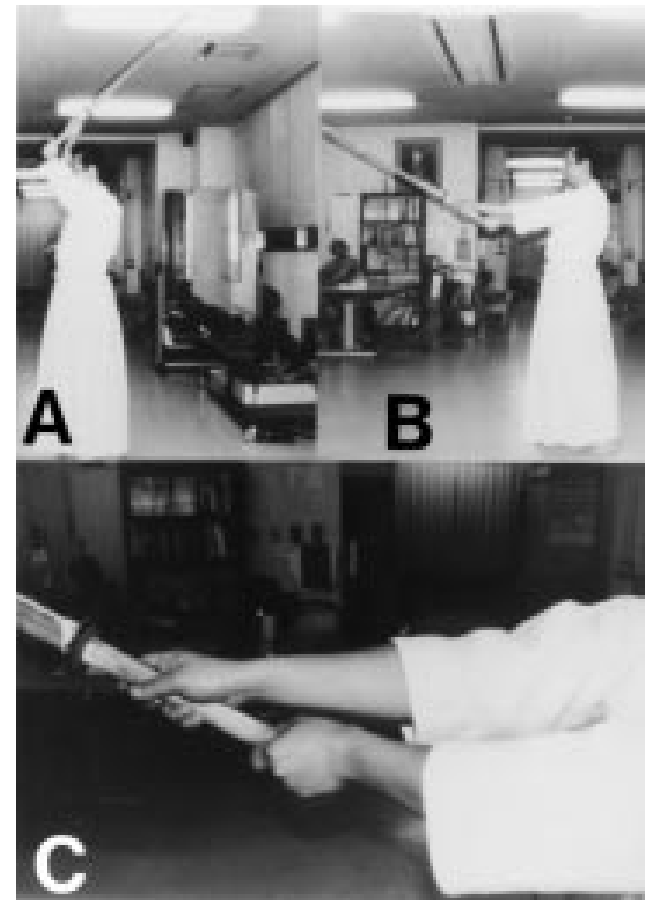

Figure 6 Lateral view of a Kendo player. He swings the sword up $(A)$ and down $(B)$ repeatedly. The proximal end of the sword is grasped with the left hand and a site further forward is grasped with the right $(C)$. 
been reported in the Japanese literature. The first case was of a 15 year old female Kendo player, ${ }^{9}$ and the second a 15 year old female synchronised swimmer. ${ }^{10}$

In Kendo, a player uses a special sword (a Sinai), which weighs about $500 \mathrm{~g}$ and is $115 \mathrm{~cm}$ long. A Kendo player grasps the sword with both hands and swings it up and down. During training, the player swings the Sinai up and down repeatedly. In the present case, as the camp represented the first experience of Kendo for the patient, we think that the excessive training caused the stress fracture of the right ulna. As he did not stop training after the onset of pain in the right forearm, he may subsequently have supported the Sinai mainly with his left hand. The continued swinging of the Sinai with the painful right forearm probably caused the bilateral stress fractures of the ulnae. The proximal end of the Sinai is grasped with the left hand and a site further forward is grasped with the right (fig 6). This probably caused the difference in the site of the stress fractures between the right and left ulna.

1 Mutoh Y, Mori T, Suzuki Y, et al. Stress fractures of the ulna in athletes. Am $\mathcal{F}$ Sports Med 1982;10:365-7.

2 Retting AC. Stress fracture of the ulna in an adolescent Retting AC. Stress fracture of the ulna in an adolescent
tournament tennis player. Am $\mathcal{F}$ Sports Med 1983;11:103-6. Hamilton HK. Stress fracture of the diaphysis of the ulna in body builder. Am f Sports Med 1984;12:405-6.

4 Bell RH, Hawkins RJ. Stress fracture of the distal ulna. Clin Orthop 1986;209:169-71.

5 Patel MR, Irizary J, Stricevic M. Stress fracture of the diaphysis: review of the literature and report of a case. $\mathcal{F}$ Hand Surg [Am] 1986;11:443-5.

6 Tanabe S, Nakahira J, Bando E, et al. Fatigue fracture of the ulna occurring in pitchers of fast-pitch softball. Am $\mathcal{F}$ Sports Med 1991;19:317-21.

7 Bollen SR, Robinson DG, Crichton KJ, et al. Stress fractures of the ulna in tennis players using a double-handed backhand stroke. Am $\mathcal{F}$ Sports Med 1993;21:751-2.

8 Koskinen SK, Mattila KT, Alanen AM, et al. Stress fracture of the ulnar diaphysis in a recreational golfer. Clinical fournal of Sports Medicine 1997;7:63-5.

9 Sakai N, Sumiya A, Watanuki C. A case of fatigue fracture of the bilateral ulnae in a school girl Kendo player. (In Japanese.) fournal of Western Fapanese Clinical Sports Medi-

10 Nagano T, Ohhata J, Sinbashi T, et al. Stress fracture of the ulna in a synchronized swimming player. (In Japanese.) fournal of Eastern Fapanese Clinical Sports Medicine 1983;4: 163-6.

\title{
Posterior dislocation of the hip while playing basketball
}

\author{
T D Tennent, A F W Chambler, D J Rossouw
}

\begin{abstract}
Injuries in basketball are usually to the ankles and knees. Dislocation of the hip is usually associated with severe traumafor example, road traffic accidents. A case is reported here in which a 22 year old club basketball player slipped on landing from a jump shot, forcing him into a side splits position from which he sustained a posterior dislocation of the hip resulting in a sciatic nerve palsy.

(Br F Sports Med 1998;32:342-343)
\end{abstract}

Keywords: basketball; hip dislocation; sciatic nerve palsy

\section{Case report}

The patient was a 22 year old club basketball player, $190 \mathrm{~cm}$ tall and weighing $80 \mathrm{~kg}$, who jumped for a ball during the first period of a club match. On landing he slipped on a wet patch on the court forcing abduction of both hips and driving his legs into a side splits position. The patient was immediately in severe pain and unable to move the left hip. He was taken to the local accident and emergency department where an $x$ ray examination confirmed the clinical diagnosis of a posterior dislocation of the left hip. At this time it was also noted that he had a palsy of the deep peroneal branch of the sciatic nerve resulting in a foot drop. The hip was reduced under a general anaesthetic within two hours of being seen by an orthopaedic surgeon. Clinically there was no evidence of any joint hypermobility and the patient could not recall any previous problems with, or injuries to, his hips. A computed tom- ography scan of the acetabulum after reduction showed no associated fractures.

After the operation there remained a persistent palsy of the common peroneal branch of the sciatic nerve with a foot drop. This was confirmed by electromyelography performed three months after the injury. At six months there was a positive Tinel's sign over the sciatic nerve in the mid-thigh suggesting some sciatic nerve recovery.

\section{Discussion}

Basketball requires strength and speed, both running and jumping being an integral part of the game. The injury rate is 88 per 1000 person years exposure, with $56 \%$ of the injuries occurring during competitive play. ${ }^{1}$ Some $31 \%$ of the injuries are to the ankle with a further $25 \%$ to the rest of the lower limb, predominantly the knee. ${ }^{1}$ To our knowledge dislocation of the hip has never been reported before in association with basketball.

Hip dislocation in the adult is uncommon and is usually the result of road traffic accidents. The "dashboard" injury in which the patella strikes the car dashboard, driving a flexed hip backwards into the acetabulum is the most common mechanism. Hip dislocation has also been reported in skiing, biking, and sledging injuries. ${ }^{2}$

Dislocation may be in a number of directions (anterior, inferior, or posterior) and may or may not be associated with acetabular fracture. Diagnosis is usually made on a clinical basis and confirmed by an anterioposterior radiograph of the pelvis. Closed reduction under a 
general anaesthetic is usually possible, although soft tissues may become interposed and require open reduction.

Sciatic nerve injury is rare, occurring in only two out of 43 consecutive patients reviewed by Dreinhofer $e t a l{ }^{2}$ The potential for recovery is related to the time to hip reduction.

After simple dislocations (those without an associated fracture), the major complications are osteoarthritis of the hip, which occurs in up to $25 \%$, and avascular necrosis of the femoral head, which develops in up to $14 \%$ of patients. ${ }^{2}$ Complete recovery of femoral head blood supply is only likely if the head is reduced within 12 hours.

The prognosis after simple hip dislocation is disputed, with rates for a "good" result ranging from $85 \%{ }^{4}$ to $40 \%,{ }^{2}$ osteoarthritis being the major long term problem.

Although this injury is thankfully rare, we suggest that the organisers and match referees are responsible for ensuring that the court remains dry throughout the match, even if this means some delay while it is cleaned. It is also the responsibility of the players to wear shoes with an appropriate sole.

If players sustain unusual hip injuries, prompt medical attention is required to reduce the chances of significant sequelae, particularly sciatic nerve injury, osteoarthritis, and avascular necrosis of the femoral head.

1 Kujala UH, Taimela S, Antti-Poika I et al. Acute injuries in soccer, ice hockey, volleyball, basketball, judo, and karate: analysis of national registry data. BMF 1995:311;1465-8.

2 Dreinhofer KE, Schwarzkoff SR, Haas NP, et al. Isolated traumatic dislocation of the hip, long term results in 50 patients. F Bone foint Surg [Br] 1994;76:6-12.

3 Hougaard K, Thomsen PB. Traumatic posterior dislocation of the hip: prognostic factors influencing the incidence of avascular necrosis of the femoral head. Arch Orthop Trauma Surg 1986;106:32-5.

4 Yang RS, Tsuang YH, Hang YS, et al. Traumatic dislocation of the hip. Clin Orthop 1991:265;218-17.

\section{Take home message}

Severe injuries in basketball are rare and medical attendance at matches is not mandatory. It is the responsibility of match officials to ensure a safe playing surface and arrange prompt medical care for injured players

\section{Commentary}

Basketball involves many combinations of sprinting, repetitive jumping, and lateral movements with sudden explosive bursts in opposite directions. ${ }^{1}$ Initially considered a non-contact sport, in recent years the amount of allowable body contact has increased, together with the size and athleticism of players participating. ${ }^{2}$ Lower extremity injuries, particularly to the knee and ankle, are common. ${ }^{2-5}$ Most injuries sustained are minor, requiring no more than 10 days missed from games or practice. ${ }^{4}$

This case identifies an injury rarely seen in sport, while also highlighting the importance of a controlled environment in preventing injury in basketball. Injury prevention measures must include the monitoring of the floor surface condition in both competitive and practice situations.

The authors also emphasise the benefit of prompt medical attention in this case. The nature of the injury mode in basketball (primarily minor) ${ }^{45}$ has meant that governing bodies have not considered medical presence mandatory at basketball matches other than major tournaments and international events. Although catastrophic injuries are not common in basketball, they do occur. Measures should be in place to ensure that, in the event of injury, trained personnel are in attendance at both practice sessions and matches to administer first line treatment.

FIONNUALA DOWNEY Musgrave Park Hospital, Belfast

1 Foran B, Pound R. Condition the NBA way. New York: Cadell \& Davies, 1994

2 Apple DF. Basketball injuries: an overview. Physician and Sportsmedicine 1988;12:64-74.

3 Purdam C. A survey of netball and basketball injuries. Excel 1987;3:9-11.

4 Caine DJ, Caine CG, Lindner KJ. Epidemiology of sports injuries. Champaign, IL: Human Kinetics Publishers, 1996.

5 High School Basketball Injury Research. Results. USA: National Athletic Trainer's Association, 1995. 


\title{
Dysbaric osteonecrosis of the shoulder in a sport scuba diver
}

\author{
Peter Wilmshurst, Kenneth Ross
}

\begin{abstract}
The previously unreported occurrence of dysbaric osteonecrosis in an amateur sport scuba diver who had no other identified cause of avascular bone necrosis is described.

(Br F Sports Med 1998;32:344-345)
\end{abstract}

Keywords: osteonecrosis; hyperbaric exposure; shoulder; scuba diver

\section{Case report}

In March 1997, a 34 year old man presented with a two and a half year history of increasing discomfort and restricted movement in his right shoulder. The symptoms had not improved with 18 months of treatment by an osteopath or local steroid injections twice in 1996. He had no history of significant injury to the shoulder. He never smoked and drank less than 20 units of alcohol a week. He started amateur sport scuba diving in September 1992 and had done 190 dives, all with compressed air. Only four dives required compulsory decompression stops; 105 dives were deeper than $30 \mathrm{~m}$, including two deeper than $40 \mathrm{~m}$. Before the start of his shoulder symptoms, most of his dives were shallower than $30 \mathrm{~m}$. All dives followed accepted safe decompression profiles. He had no symptoms suggesting decompression illness. Radiography of the right shoulder showed flattening of the humeral head with patchy sclerosis and slight fragmentation in keeping with avascular bone necrosis. A magnetic resonance imaging scan of the shoulder (fig 1) showed partial collapse of the articular surface of the humerus with loss of articular cartilage, typical of advanced avascular necrosis. Scans of both hips were normal. 10 June 1998

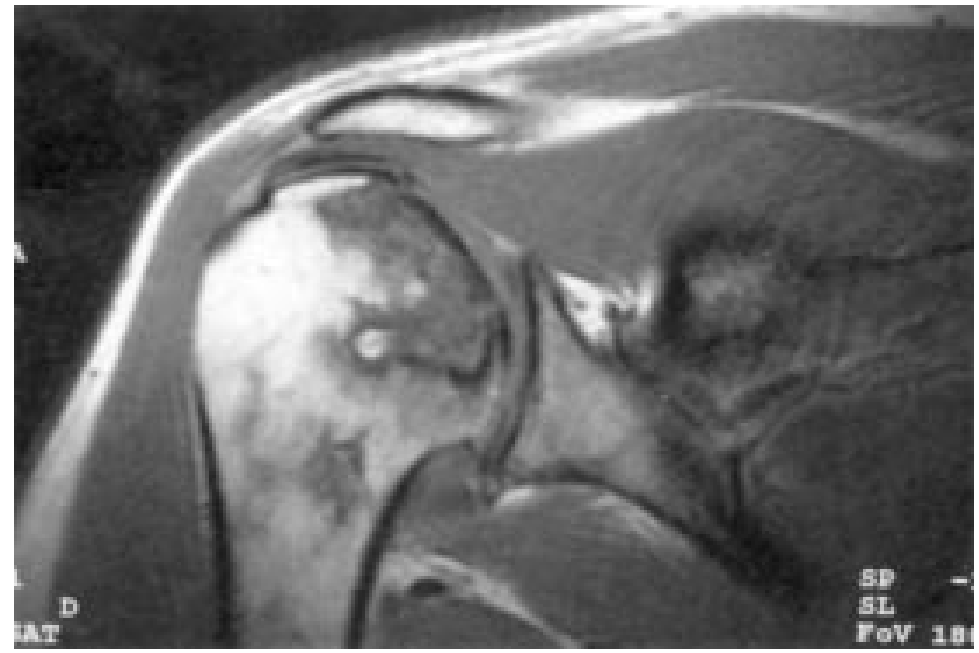

Figure 1 Magnetic resonance image of the right shoulder showing avascular necrosis.
Haemoglobin concentration, erythrocyte sedimentation rate, liver function, thyroid function, urate concentration, fasting concentrations of lipids and glucose, and antinuclear antibody were normal. Contrast echocardiography showed no evidence of an intracardiac shunt. Chest $x$ ray findings and lung spirometry, flowvolume loops, and transfer factor were normal.

\section{Discussion}

Avascular bone necrosis is an occupational illness in professional divers and caisson workers, when it is usually known as dysbaric osteonecrosis. It occurs months to decades after hyperbaric exposure. If lesions are juxtaarticular, severe joint degeneration can result. When lesions affect bone shafts, they are asymptomatic. Asymptomatic lesions are a cause for concern because dysbaric osteonecrosis and medullary bone infarcts in general may undergo malignant change. ${ }^{12}$ The pathogenesis of dysbaric osteonecrosis is unknown. There is no proven association with decompression illness, although both can affect joints and the risk of each condition is related to the degree of exposure to hyperbaric conditions. The incidence of dysbaric osteonecrosis increases with depth (absolute pressures) and the duration or number of exposures. ${ }^{3}$ However, dysbaric osteonecrosis has been described after a single long hyperbaric exposure with rapid decompression. ${ }^{4}$

Amateur sport scuba divers are considered to be at low risk because their dives are usually short and shallow. Dysbaric osteonecrosis has been described once before in an amateur sport scuba diver, but in that case the diver had two other risk factors for avascular necrosis: diabetes and trauma. ${ }^{5}$ The case we describe had no other risk factor for avascular necrosis besides hyperbaric exposure. The humeral head was the site of avascular necrosis in our case and that reported by Gorman and Sandow. ${ }^{5}$ This is the commonest site for juxta-articular dysbaric osteonecrosis, ${ }^{26}$ but it is a rare site for avascular necrosis with other aetiologies. This suggests that the avascular necrosis in these two amateur scuba divers was the result of hyperbaric exposure, even though their exposures were conservative. As amateur divers go deeper, for longer, and use gas mixtures containing helium, it is probable that more cases of dysbaric osteonecrosis will occur. The interval between exposure and the first symptoms of dysbaric osteonecrosis is usually longer than in the case we describe. Failure to learn from past lessons may cause amateur divers to suffer an epidemic of dysbaric osteonecrosis, similar to those in caisson workers in the last century and in 
professional divers earlier in this century, before safer work practices were introduced to those occupations.

1 Galli SJ, Weintraub HP, Proppe KH. Malignant fibrous histiocyoma and pleomorphic sarcoma in association with medullary bone infarcts. Cancer 1978;41:607-19.

2 Kitano M, Iwasaki H, Yoh SS, et al. Malignant fibrous histiocytoma at site of bone infarction in association with DCS. Undersea Biomed Res 1984;11:305-14.
3 Decompression Sickness Central Registry and Radiological Panel. Aseptic bone necrosis in commercial divers. Lancet 1981;ii:384-8.

4 James CCM. Late bone changes in caisson disease. Three cases in submarine personnel. Lancet 1945;ii:6-8.

5 Gorman DF, Sandow MJ. Posterior shoulder dislocation and humeral head necrosis in a recreational scuba diver with diabetes. Undersea Biomed Res 1992;19:457-61.

6 Davidson JK. Dysbaric disorders: aseptic bone necrosis in tunnel workers and divers. Bailliere's Clin Rheumatol 1989; $3: 1-23$.

\section{Commentary}

Scuba diving is an increasingly popular sport world wide. Most people who participate do so without any ill effects. However, the medical risks of an environment that imposes unique physical, physiological, and psychological stresses on the body should not be forgotten. Research into chronic medical conditions caused by pressure in the sport scuba diver has been limited. Recent papers have looked at long term damage in the central nervous system ${ }^{1}$ and the eye ${ }^{2}$ but a paper in this journal is a reminder that the sport scuba diver is susceptible to dysbaric osteonecrosis, just as the professional diver is. It is clear that the underlying causes of this condition are unknown and that this is an interesting area for research. The recent call by the Health and Safety Executive for proposals for research into the long term health effects of diving is a welcome step in this direction, especially as some in the scuba diving community are using helium gas mixtures in an effort to reach ever greater depths.

C EDGE

Drayton, Oxon

1 Knauth M, Ries S, Pohimann S, et al. Cohort study of multiple brain lesions in sport divers: role of a patent foramen ovale. $B M \mathcal{F}$ 1997;314:701-5.

2 Polkinghorne PJ, Sehmi K, Cross MR, et al. Ocular fundus lesions in divers. Lancet 1988;ii:1381-3. 